\title{
Noninvasive mapping before surgical ablation for persistent, long-standing atrial fibrillation
}

Marek P. Ehrlich, MD, ${ }^{\mathrm{a}}$ Guenther Laufer, MD, ${ }^{\mathrm{a}}$ Iuliana Coti, MD, ${ }^{\mathrm{a}}$ Markus Peter, Eng, ${ }^{\mathrm{b}}$

Martin Andreas, MD, PhD, ${ }^{\mathrm{a}}$ Guenter Stix, MD, ${ }^{\mathrm{c}}$ and Niv Ad, $\mathrm{MD}^{\mathrm{d}, \mathrm{e}}$

\section{ABSTRACT}

Objective: The study objective was to study the electrophysiologic mechanism of atrial fibrillation using a noninvasive, beat-by-beat, 3-dimensional mapping technique in patients with persistent and long-standing persistent atrial fibrillation undergoing concomitant surgical ablation.

Methods: In this pilot trial, 10 patients (6 male; mean age, $70 \pm 10$ years) with persistent atrial fibrillation were mapped preoperatively with a noninvasive surface system (ECVUE, CardioInsight, Medtronic Inc, Minneapolis, Minn). Eight patients were candidates for mitral valve surgery, 1 patient was a candidate for aortic valve and ascending aortic replacement, and 1 patient was a candidate for coronary bypass surgery. In 5 patients, tricuspid valve repair was also performed. The Cox-Maze III/IV was performed using combined cryoablation and bipolar radiofrequency, and the left appendage was removed in all cases. The median preprocedural duration of atrial fibrillation was 30 months, and the diameter of the left atrium was $63 \mathrm{~mm}$. Atrial regions were divided according to the Bordeaux classification.

Results: Preoperative mapping was successful in all patients with clear identification of the potential mechanism of atrial fibrillation. Biatrial pathology was recognized in all subjects. Rotor and macro re-entry activity were present in all patients, whereas focal activity was demonstrated in only 6 patients. Rotor activity in the right atrium was documented in all patients.

Conclusions: This is the first report on the preoperative use of the ECUVE in surgical candidates for concomitant surgical procedures. The fact that a biatrial mechanism for atrial fibrillation was detected in all patients emphasizes the importance of a Cox-Maze III/IV procedure to treat patients with valvular heart disease and nonparoxysmal atrial fibrillation. Preoperative mapping has the potential to significantly improve our understanding of the pathophysiology in atrial fibrillation and better guide the surgical ablation procedure of choice in a single patient. (J Thorac Cardiovasc Surg 2019;157:248-56)

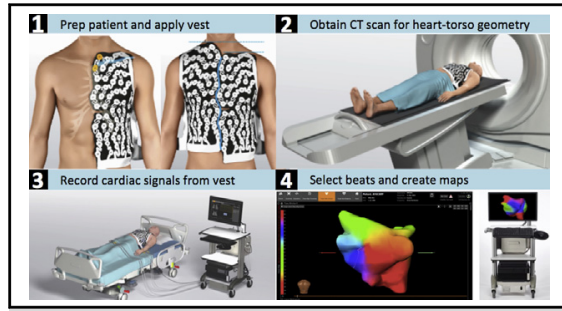

Rotor activity in all 10 patients.

\section{Central Message}

We assess the mechanism of paroxysmal $\mathrm{AF}$ with a noninvasive, 3-dimensional, beat-bybeat mapping technique.

\section{Perspective}

Biatrial pathology was recognized in all subjects. Rotor activity in the right atrium was documented in all patients. The fact that a biatrial mechanism for AF was detected in all patients emphasizes the importance of a Cox-Maze III/IV procedure.

See Editorial Commentary page 257.

See Editorial page 232.
Atrial fibrillation (AF) is the most common clinically encountered arrhythmia and is a major cause of morbidity and mortality. ${ }^{1}$ In most cases, standard medical therapy is

\footnotetext{
From the Departments of ${ }^{\mathrm{a} C a r d i a c}$ Surgery and ${ }^{\mathrm{c}}$ Cardiology, University of Vienna, Vienna, Austria; ${ }^{\mathrm{b}}$ Medtronic $\mathrm{GmbH}$, Meerbusch, Germany; ${ }^{\mathrm{d}}$ Washington Adventist Hospital, Takoma Park, Md; and ${ }^{\mathrm{e}}$ West Virginia University, Morgantown, WVa.

Received for publication March 14, 2018; revisions received July 22, 2018; accepted for publication July 23, 2018; available ahead of print Oct 25, 2018.

Address for reprints: Marek P. Ehrlich, MD, Department of Cardiac Surgery, Medical University of Vienna, Waehringer Guertel 18-20, A-1090 Vienna, Austria (E-mail: marek.ehrlich@muv.ac.at).

0022-5223/\$36.00

Copyright (c) 2018 by The American Association for Thoracic Surgery

https://doi.org/10.1016/j.jtcvs.2018.07.104
}

not effective or is poorly tolerated. ${ }^{2}$ The best catheter and surgical-based approaches to treat AF are still under debate. However, the Cox-Maze procedure is the intervention that is associated with the highest long-term success rate. Experimental and clinical data suggest that focal and rotational driver sources in both atria may be critical and responsible in maintaining $\mathrm{AF}^{3-5}$

- Scanning this $\mathrm{QR}$ code will take you to the article title page to access supplementary information.

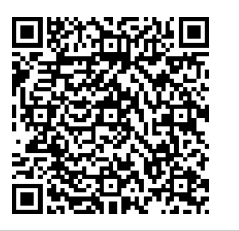




\section{Abbreviations and Acronyms \\ $\mathrm{AF}=$ atrial fibrillation \\ $\mathrm{PV}=$ pulmonary vein}

Noninvasive phase mapping is a relatively new tool. It allows high-resolution simultaneous recording of biatrial $\mathrm{AF}$ activation sequences under circumstances close to normal physiologic conditions. ${ }^{6}$ This method has been used in the last 5 years solely in patients with lone AF undergoing catheter ablation. ${ }^{7,8}$ In general, there is not an electrophysiologic study to better understand the mechanism of the atrial arrhythmia in the subgroup of patients who are candidates for surgical ablation of AF in conjunction with another procedure (eg, valve, coronary artery bypass grafting). This is probably a combination of the practice set-up and the invasiveness of catheter-based mapping. In theory, mapping may shed light on the potential mechanism in such patients and improve our understanding of the pathophysiology of AF to better plan the appropriate procedure. The introduction of the noninvasive, 3-dimensional, high-density mapping system allows surgeons and electrophysiologists to map patients before procedures and better understand and plan the surgical ablation procedure. The present study aimed to investigate the anatomic distribution of re-entrant and focal drivers in surgical patients with mitral and aortic valve pathology and AF candidates for concomitant valve surgery and surgical ablation (Video 1).

\section{MAPPING TECHNIQUE}

The signal acquisition from the patient and subsequent computational methods were used in the reconstruction of noninvasive maps obtained by multiple torso electrodes using the ECVUE CardioInsight device (Medtronic Inc, Minneapolis, Minn). ${ }^{9}$ Briefly, a 252-electrode vest is applied to the patient's torso and connected to the noninvasive imaging system, and surface potentials are recorded (Figure 1). This is followed by a noncontrast thoracic computed tomography scan to obtain high-resolution images of the heart and the vest electrodes. The 3-dimensional epicardial bicameral atria geometries are reconstructed from segmental computed tomography images. The relative positions of body surface electrodes can be visualized on the torso geometry. The system reconstructs epicardial potentials, unipolar electrograms, potential activation (isochrone images), and directional activation maps in every beat/cycle using preconstructed mathematical reconstruction algorithms. Details of the mathematical methods have been provided in a previous publication. ${ }^{10}$ The first 7 patients were mapped and analyzed with the original version of the software (Version 1.0), and the last 3 patients were analyzed with the next release of the software (Version 1.1).

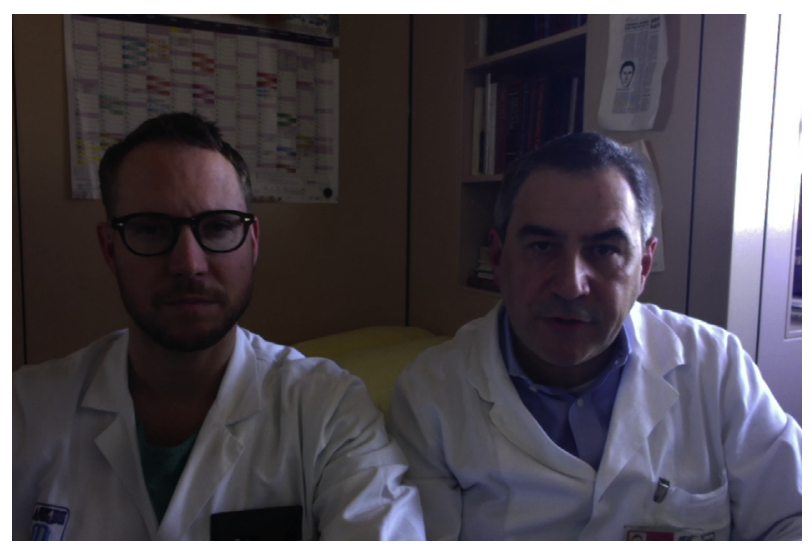

VIDEO 1. A brief presentation of the study purpose. Video available at: https://www.jtcvs.org/article/S0022-5223(18)32467-X/fulltext.

In patients with a faster heart rate and a T-R interval less than $800 \mathrm{~ms}$, pharmacologic intervention with beta-blockers (metoprolol or esmolol) was induced because a minimum T-R electrocardiogram interval of $800 \mathrm{~ms}$ is necessary to perform the mapping.

\section{PATIENTS AND METHODS}

From February 2017 to January 2018, 10 patients with mitral or tricuspid insufficiency, 1 patient with aortic stenosis and ascending aortic aneurysm, and 1 patient with coronary vessel disease were mapped preoperatively with the ECVUE CardioInsight device (Medtronic Inc). All 10 patients had persistent AF. All 8 patients with valvular disease had severe mitral insufficiency due to posterior leaflet prolapse $(n=6)$ or rheumatic mitral disease $(\mathrm{n}=2)$. In addition, 5 of these 8 patients $(62 \%)$ had severe tricuspid insufficiency due to annular dilatation. The median preprocedural duration of AF was 30 months, and the diameter of the left atrium was $63 \mathrm{~mm}$. The patients' clinical profiles are shown in Table 1. Surgery was performed through a median sternotomy with cardiopulmonary bypass and cardioplegic arrest. Perioperative major complications were considered to be reoperation for bleeding, prolonged ventilatory support, renal failure requiring dialysis, mediastinitis, perioperative transient ischemic attack or stroke, and perioperative myocardial infarction. This study was approved by the University of Vienna Ethical Committee (Number: ECS 1046/2018).

\section{RESULTS}

\section{Preoperative Mapping}

All patients were successfully mapped with the system 1 to 51 days (median, 10 days) before surgery. Five patients $(50 \%)$ required pharmacologic intervention (beta-blockade) to slow down the heart rate (heart rate, $\sim 60-70$ beats $/ \mathrm{min}$ ) to allow appropriate and reliable data recording and a sufficient phase mapping. A total of 193 phase windows were analyzed, resulting in a total recording time of 192 seconds (minimum, 15 seconds; maximum, 23 seconds).

\section{Anatomic Distribution of Drivers}

The Bordeaux region classification of both atria was used to localize focal and rotor driver activity (Figure 2). In total, 289 re-entrant and 15 focal drivers were mapped. 


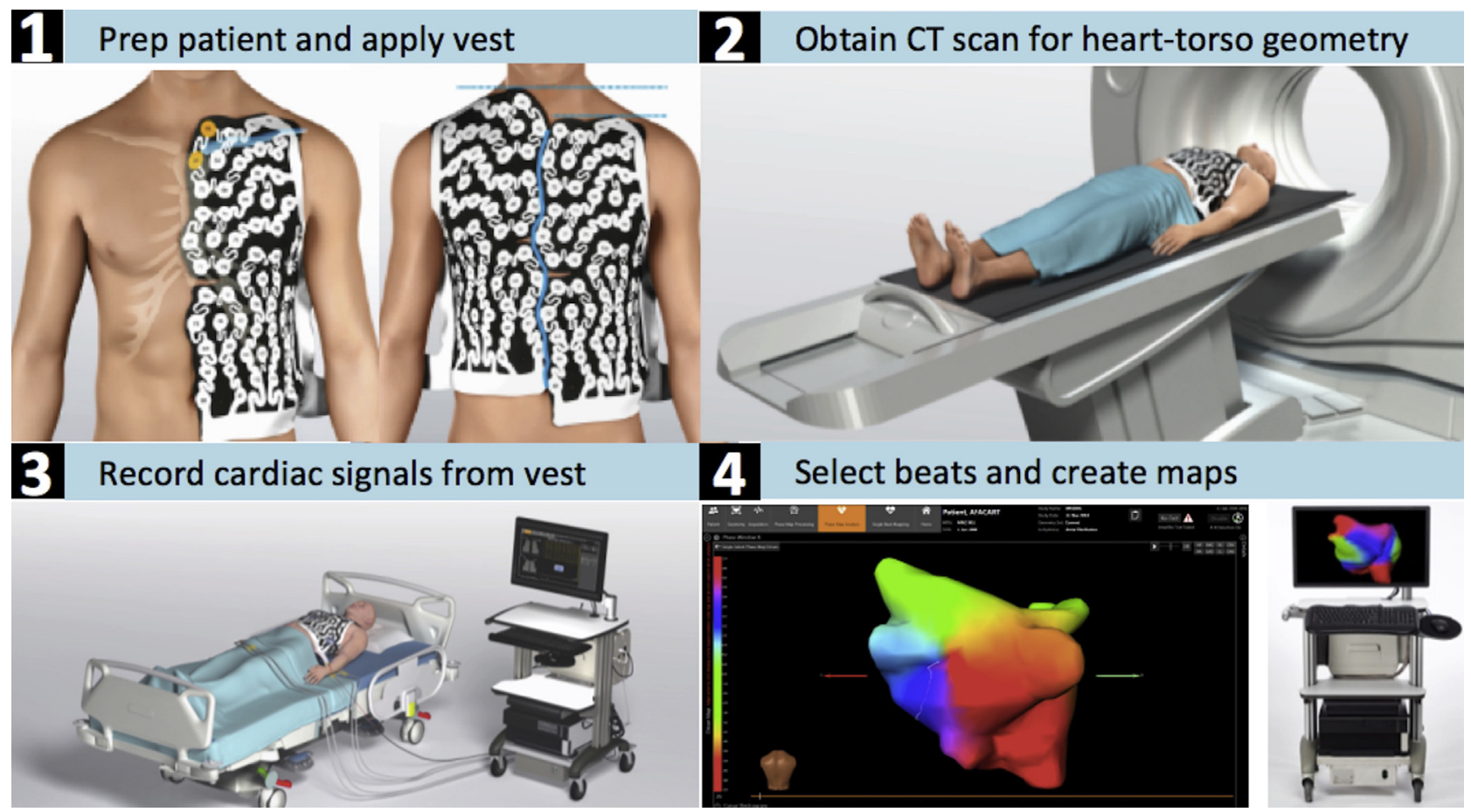

FIGURE 1. CardioInsight mapping system (Medtronic Inc, Minneapolis, Minn). $C T$, Computed tomography.

Tables 2 and 3 show the distribution of focal and rotor drivers in each region. Focal activity was seen in 6 of 10 patients $(60 \%)$. Only 2 patients had a focal activity in the

TABLE 1. Patient characteristics

\begin{tabular}{|c|c|}
\hline Characteristics & $(\mathbf{n}=10)$ \\
\hline Mean age $\pm \mathrm{SD}$ & $70 \pm 10$ \\
\hline Female & $4(40 \%)$ \\
\hline Ejection fraction $(\%) \pm \mathrm{SD}$ & $57 \% \pm 6 \%$ \\
\hline Diabetes & $0(0 \%)$ \\
\hline Body mass index & $24.9 \mathrm{~kg} / \mathrm{m}^{2}$ \\
\hline Hypertension & $6(60 \%)$ \\
\hline Peripheral vascular disease & 0 \\
\hline Previous cerebrovascular accident & 0 \\
\hline Chronic pulmonary disease & $4(40 \%)$ \\
\hline Mean left atrial size $(\mathrm{mm}) \pm \mathrm{SD}$ & $60 \pm 11 \mathrm{~mm}$ \\
\hline Mean right atrial size $(\mathrm{mm}) \pm \mathrm{SD}$ & $70 \pm 8 \mathrm{~mm}$ \\
\hline Mean right ventricular size $(\mathrm{mm}) \pm \mathrm{SD}$ & $37 \pm 3 \mathrm{~mm}$ \\
\hline $\begin{array}{l}\text { Mean systolic pulmonary artery pressure } \\
\qquad(\mathrm{mm} \mathrm{Hg}) \pm \mathrm{SD}\end{array}$ & $48 \pm 13 \mathrm{~mm}$ \\
\hline Median duration of AF (mo, min, max) & $30(5180)$ \\
\hline Long-standing persistent AF type & 4 \\
\hline euroSCORE II ( $\%)$ & 5 \\
\hline Concomitant $\mathrm{CABG}$ procedure & 1 \\
\hline Concomitant aortic procedure & 1 \\
\hline
\end{tabular}

$S D$, Standard deviation; $A F$, atrial fibrillation; euroSCORE, European System for Cardiac Operative Risk Evaluation; $C A B G$, coronary artery bypass grafting. right atrium (Figure 3 ). The most prominent driver regions were the pulmonary vein (PV) area (Figure 4). When both re-entrant and focal drivers were added together, the drivers were located in region 1 in $19 \%$ and in region 2 in $27 \%$ of all activities. All 10 patients had rotor activities in the right atrium. Rotor activities were located in the upper half of the right atrium and appendage in 9 patients and in the lower part of the right atrium in 6 of 10 patients. Five patients $(50 \%)$ had rotors in both regions of the right atrium. Table 4 shows the amount of rotors in the right atrium. Three patients $(30 \%)$ had only 1 rotor, 1 patient had 4 rotors, 1 patient had 5 rotors, 1 patient had 7 rotors, 2 patients had 8 rotors, 1 patient had 9 rotors, and 1 patient had 36 rotors. The number of total rotors in both atria in relationship to the duration of AF is shown in Table 5. Table 6 shows the relationship of the presenting cardiac pathology and the electrophysiology mapping by right and left atria.

\section{Surgical Procedures}

The Cox-Maze III/IV was performed using combined cryoablation and bipolar radiofrequency, and the left appendage was removed in all cases. Six patients received mitral valve repair, and 2 patients mitral valve replacement with a biological and mechanical valve due to mitral regurgitation. Four of these 8 patients had additional tricuspid valve repair. The ninth patient underwent replacement of his aortic valve and ascending aorta due to aortic stenosis and aortic aneurysm $(58 \mathrm{~mm})$. The tenth patient underwent coronary artery bypass grafting. 

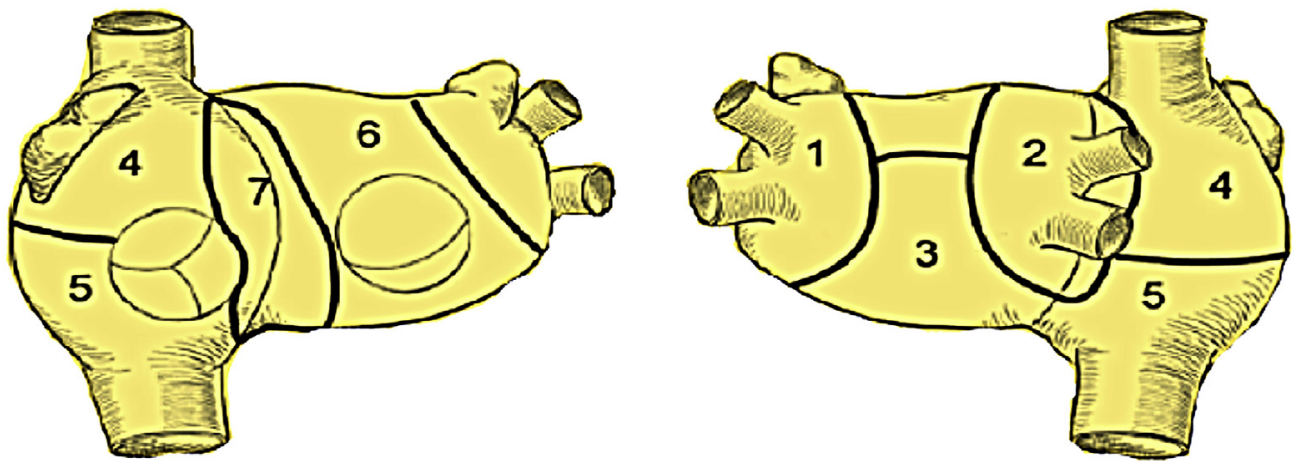

FIGURE 2. Bordeaux atrial region classification. Biatrial schema is divided into 7 regions: 1, left PVs and left appendage; 2 , right PVs and posterior interatrial groove; 3, inferior and posterior left atrium; 4, upper half of right atrium and appendage; 5, lower half of right atrium; 6, anterior left atrium and roof; 7, anterior interatrial groove.

TABLE 2. Number and area of focal activity in all 10 patients

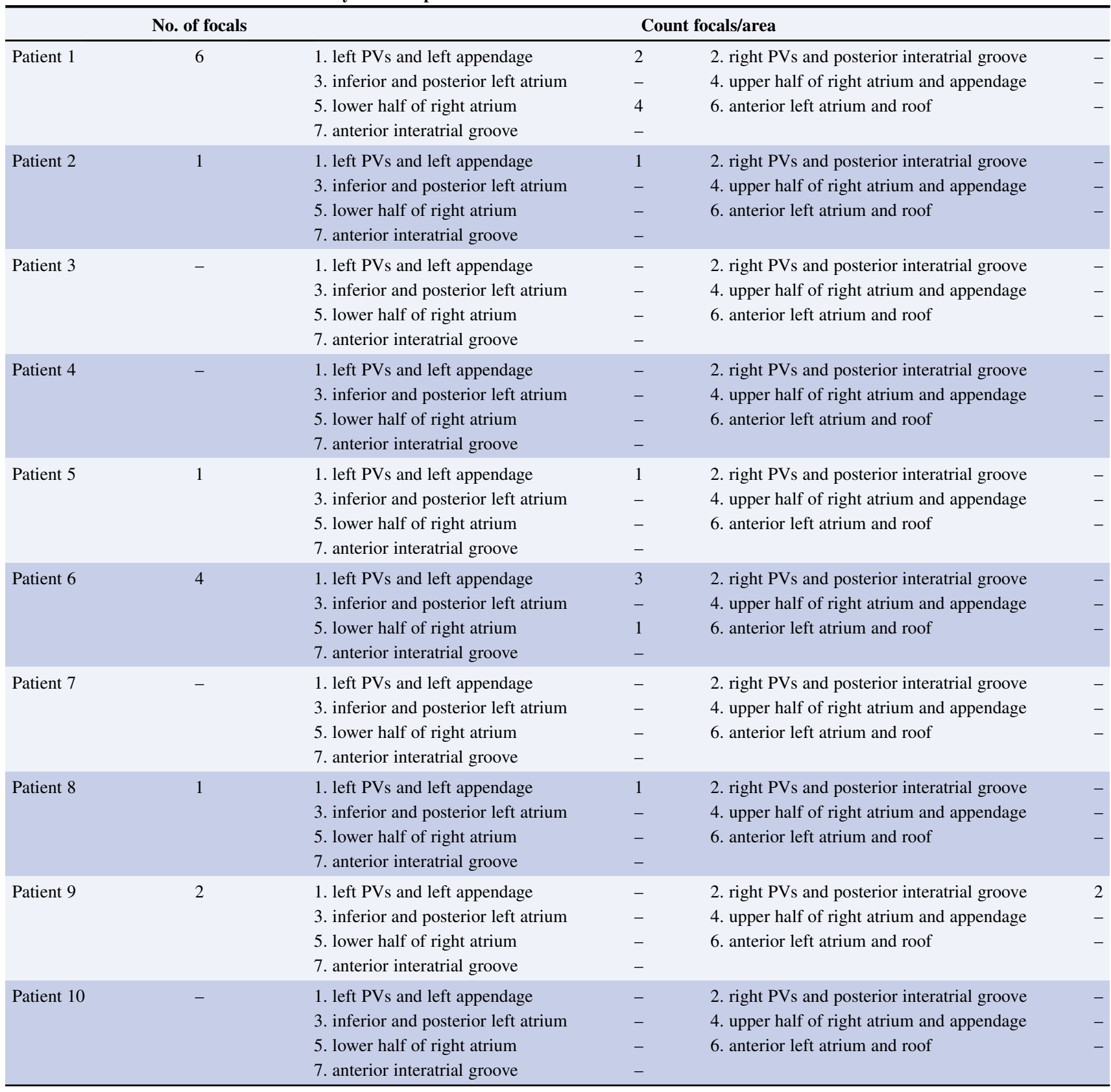

$P V$, Pulmonary vein. 
TABLE 3. Number and area of rotor activity in all 10 patients

\begin{tabular}{|c|c|c|c|c|c|c|}
\hline \multirow{2}{*}{$\begin{array}{l}\begin{array}{l}\text { No. of } \\
\text { rotors }\end{array} \\
18\end{array}$} & \multicolumn{4}{|c|}{ Count rotors/area } & \multirow{2}{*}{$\begin{array}{c}\begin{array}{c}\text { No. of phase } \\
\text { windows }\end{array} \\
15\end{array}$} & \multirow{2}{*}{$\frac{\sum \text { length }[\mathbf{s}]}{17,137}$} \\
\hline & 1. left PVs and left appendage & 4 & 2. right PVs and posterior interatrial groove & 9 & & \\
\hline & 3. inferior and posterior left atrium & 4 & 4. upper half of right atrium and appendage & 1 & & \\
\hline & 5. lower half of right atrium & - & 6. anterior left atrium and roof & - & & \\
\hline & 7. anterior interatrial groove & - & & & & \\
\hline \multirow[t]{4}{*}{19} & 1. left PVs and left appendage & 4 & 2. right PVs and posterior interatrial groove & 6 & 24 & 23,252 \\
\hline & 3. inferior and posterior left atrium & 3 & 4. upper half of right atrium and appendage & 2 & & \\
\hline & 5. lower half of right atrium & 3 & 6. anterior left atrium and roof & - & & \\
\hline & 7. anterior interatrial groove & 1 & & & & \\
\hline \multirow[t]{4}{*}{27} & 1. left PVs and left appendage & 6 & 2. right PVs and posterior interatrial groove & 4 & 21 & 22,374 \\
\hline & 3. inferior and posterior left atrium & 3 & 4. upper half of right atrium and appendage & 7 & & \\
\hline & 5. lower half of right atrium & 1 & 6. anterior left atrium and roof & 1 & & \\
\hline & 7. anterior interatrial groove & 5 & & & & \\
\hline \multirow[t]{4}{*}{20} & 1. left PVs and left appendage & 7 & 2. right PVs and posterior interatrial groove & 8 & 20 & 17,156 \\
\hline & 3. inferior and posterior left atrium & 1 & 4. upper half of right atrium and appendage & 4 & & \\
\hline & 5. lower half of right atrium & - & 6. anterior left atrium and roof & - & & \\
\hline & 7. anterior interatrial groove & - & & & & \\
\hline \multirow[t]{4}{*}{21} & 1. left PVs and left appendage & 3 & 2. right PVs and posterior interatrial groove & 5 & 22 & 19,703 \\
\hline & 3. inferior and posterior left atrium & 6 & 4. upper half of right atrium and appendage & - & & \\
\hline & 5. lower half of right atrium & 1 & 6. anterior left atrium and roof & - & & \\
\hline & 7. anterior interatrial groove & 6 & & & & \\
\hline \multirow[t]{4}{*}{19} & 1. left PVs and left appendage & 2 & 2. right PVs and posterior interatrial groove & 3 & 15 & 20,799 \\
\hline & 3. inferior and posterior left atrium & 3 & 4. upper half of right atrium and appendage & 2 & & \\
\hline & 5. lower half of right atrium & 5 & 6. anterior left atrium and roof & - & & \\
\hline & 7. anterior interatrial groove & 4 & & & & \\
\hline \multirow[t]{4}{*}{22} & 1. left PVs and left appendage & - & 2. right PVs and posterior interatrial groove & 5 & 30 & 18,365 \\
\hline & 3. inferior and posterior left atrium & 4 & 4. upper half of right atrium and appendage & 5 & & \\
\hline & 5. lower half of right atrium & 4 & 6. anterior left atrium and roof & - & & \\
\hline & 7. anterior interatrial groove & 4 & & & & \\
\hline \multirow[t]{4}{*}{92} & 1. left PVs and left appendage & 11 & 2. right PVs and posterior interatrial groove & 24 & 15 & 18,517 \\
\hline & 3. inferior and posterior left atrium & 15 & 4. upper half of right atrium and appendage & 25 & & \\
\hline & 5. lower half of right atrium & 11 & 6. anterior left atrium and roof & 1 & & \\
\hline & 7. anterior interatrial groove & 5 & & & & \\
\hline \multirow[t]{4}{*}{20} & 1. left PVs and left appendage & 3 & 2. right PVs and posterior interatrial groove & 8 & 16 & 15,253 \\
\hline & 3. inferior and posterior left atrium & 6 & 4. upper half of right atrium and appendage & 1 & & \\
\hline & 5. lower half of right atrium & - & 6. anterior left atrium and roof & 1 & & \\
\hline & 7. anterior interatrial groove & 1 & & & & \\
\hline \multirow[t]{4}{*}{31} & 1. left PVs and left appendage & 11 & 2. right PVs and posterior interatrial groove & 7 & 15 & 21,429 \\
\hline & 3. inferior and posterior left atrium & 5 & 4. upper half of right atrium and appendage & 4 & & \\
\hline & 5. lower half of right atrium & - & 6. anterior left atrium and roof & - & & \\
\hline & 7. anterior interatrial groove & 4 & & & & \\
\hline
\end{tabular}

$P V$, Pulmonary vein.

\section{Follow-up}

A total of 9 of the 10 patients $(90 \%)$ were discharged from the hospital in sinus rhythm. One patient had a prolonged intensive care stay ( 9 weeks) because of postoperative bleeding, consecutive renal failure, and a reversible neurologic deficit. He was discharged in AF to a secondary hospital and died 75 days postoperatively. One patient died of hemorrhagic cerebral bleeding on day 31 postoperatively.

To date, the remaining 8 patients have received a 24-hour Holter electrocardiogram 3 months postoperatively and 6 of the 8 patients $(75 \%)$ were in sinus rhythm. Their antiarrhythmic drugs were discontinued at the time. Two patients were still in AF. One patient had a cardioversion and is now in sinus rhythm with an antiarrhythmic drug. The other patient is in atrial flutter and will receive a catheter ablation.

\section{DISCUSSION}

AF represents the most frequently observed rhythm disorder worldwide, affecting $1 \%$ to $2 \%$ of adults, and its 


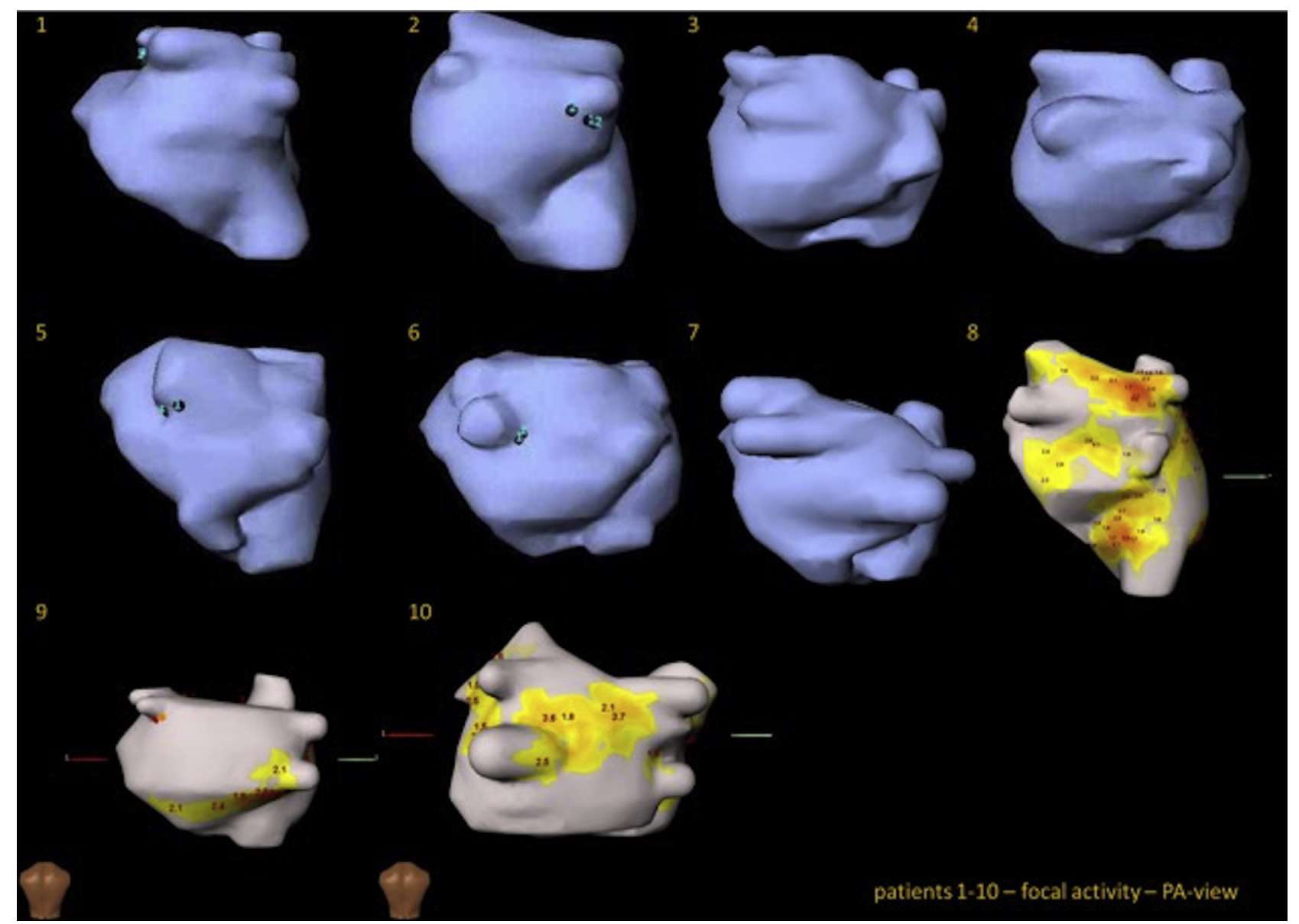

FIGURE 3. Focal activity of all 10 patients. The first 7 patients were mapped with the first released version of the software, and the last 3 patients were already mapped with the upgraded version of the software: posterior anterior view.

incidence increases with age. $\mathrm{AF}$ is associated with an increased risk of heart failure, reduced survival, diminished quality of life, and significant increase in the risk for thromboembolic events. ${ }^{11}$

The exact pathophysiologic mechanisms associated with AF are still under debate and may vary in different patients. However, there are a few hypotheses that consider atrial pathologies, automatic foci, and multiple wavelets as triggers. Although the focal activity theory was acknowledged as the main trigger for paroxysmal $\mathrm{AF}$, different mechanisms are involved in long-standing persistent AF. ${ }^{12}$

The Cox-Maze procedure is an effective treatment modality for $\mathrm{AF}$ in patients undergoing cardiac surgery and yields excellent mid- to long-term results in experienced hands. ${ }^{13,14}$ The original operation was aimed to treat both atria with an anatomic approach composed of a specific biatrial lesion set. The cut-and-sew technique was overtaken by alternative energy sources, such as radiofrequency and cryothermia, to achieve transmural lesion sets. The success rate has been reported with excellent mid- to long-term results. However, there have been several reports lately in which limited lesion sets were created, especially on the left atrial side, with only good results. ${ }^{15,16}$

New technologies have been described recently that allow direct visualization of the mechanisms driving AF, thereby allowing more focused delivery of ablation. ${ }^{6}$ In particular, novel developments have allowed biatrial panoramic AF mapping using phase-based analysis of epicardial potentials. In a European multicenter trial, the distribution and characteristics of drivers were analyzed before the intervention. ${ }^{17}$ Although the PVs were a frequent site of drivers in this study, approximately two-thirds of drivers were found in non-PV sites, and a significant proportion of these were found in the right atrium. This point was emphasized by the fact that AF terminated in non-PV sites in the majority $(63 \%)$ of terminations, with the right atrium being the site of termination in $28 \%$ of acutely successful cases. Driver distribution varied considerably among patients, supporting the idea of a more specific patient-based ablation approach facilitated by the panoramic mapping system.

In patients receiving concomitant surgical ablation or valve and coronary bypass surgery, there is almost no 
TABLE 4. Number and location of rotor activity in the right atrium

\begin{tabular}{|c|c|c|c|}
\hline Patients & Location of rotor activity & No. of rotors in each location & Total No. of rotors \\
\hline \multirow[t]{2}{*}{ Patient 1} & Upper half of right atrium and appendage & 1 & 1 \\
\hline & Lower half of right atrium & 0 & \\
\hline \multirow[t]{2}{*}{ Patient 2} & Upper half of right atrium and appendage & 2 & 5 \\
\hline & Lower half of right atrium & 3 & \\
\hline \multirow[t]{2}{*}{ Patient 3} & Upper half of right atrium and appendage & 7 & 8 \\
\hline & Lower half of right atrium & 1 & \\
\hline \multirow[t]{2}{*}{ Patient 4} & Upper half of right atrium and appendage & 4 & 4 \\
\hline & Lower half of right atrium & 0 & \\
\hline \multirow[t]{2}{*}{ Patient 5} & Upper half of right atrium and appendage & 0 & 1 \\
\hline & Lower half of right atrium & 1 & \\
\hline \multirow[t]{2}{*}{ Patient 6} & Upper half of right atrium and appendage & 2 & 7 \\
\hline & Lower half of right atrium & 5 & \\
\hline \multirow[t]{2}{*}{ Patient 7} & Upper half of right atrium and appendage & 5 & 9 \\
\hline & Lower half of right atrium & 4 & \\
\hline \multirow[t]{2}{*}{ Patient 8} & Upper half of right atrium and appendage & 25 & 36 \\
\hline & Lower half of right atrium & 11 & \\
\hline \multirow[t]{2}{*}{ Patient 9} & Upper half of right atrium and appendage & 1 & 1 \\
\hline & Lower half of right atrium & 0 & \\
\hline \multirow[t]{2}{*}{ Patient 10} & Upper half of right atrium and appendage & 4 & 8 \\
\hline & Lower half of right atrium & 4 & \\
\hline
\end{tabular}

information on the pathophysiology of their AF. This is mainly because the majority of them will never be fully assessed by an electrophysiologist and have a full electrophysiologic study. In this unique study, we used the CardioInsight ECVUE system in cardiac surgical patients undergoing the Cox-Maze procedure for persistent and long-standing AF. Although this is a small study with some preliminary data and definitely requires more investigation, 2 major findings could be demonstrated. First and most important, we showed, as proven by the Non-Invasive Mapping Before Ablation for Atrial Fibrillation (AFACART) trial, that there are rotors in both

TABLE 5. Number of total rotors in both atria in relationship to the duration of atrial fibrillation

\begin{tabular}{lcc}
\hline Patients & No. of rotors & Duration of AF (mo) \\
\hline Patient 1 & 18 & 36 \\
\hline Patient 2 & 19 & 60 \\
\hline Patient 3 & 27 & 42 \\
\hline Patient 4 & 20 & 6 \\
\hline Patient 5 & 21 & 180 \\
\hline Patient 6 & 19 & 5 \\
\hline Patient 7 & 22 & 72 \\
\hline Patient 8 & 92 & 14 \\
\hline Patient 9 & 20 & 6 \\
\hline Patient 10 & 31 & 24 \\
\hline
\end{tabular}

$A F$, Atrial fibrillation. right and left atria in all mapped patients presenting with persistent AF. This implies that isolated PV isolation and left atrial lesion sets alone might not be sufficient for this patient cohort. This finding is in contrast with the study by Gillinov and colleagues, ${ }^{9}$ which described no difference with regard to outcomes between the PV isolation group and the biatrial lesion sets, although the overall success reported in the study is low. ${ }^{15}$ However, their study was not intended to compare these subgroups and was furthermore underpowered, which therefore limits the comparison. Our results also need to be interpreted with caution,

TABLE 6. Relationship of presenting pathology to the location of rotors

\begin{tabular}{llcc}
\hline Patients & $\begin{array}{c}\text { Presenting } \\
\text { pathology }\end{array}$ & $\begin{array}{c}\text { Left-sided } \\
\text { rotors }\end{array}$ & $\begin{array}{c}\text { Right-sided } \\
\text { rotors }\end{array}$ \\
\hline Patient 1 & MI, TI & 17 & 1 \\
\hline Patient 2 & MI & 14 & 5 \\
\hline Patient 3 & MI, TI & 19 & 8 \\
\hline Patient 4 & CHD & 16 & 4 \\
\hline Patient 5 & MI & 20 & 1 \\
\hline Patient 6 & MI, TI & 12 & 7 \\
\hline Patient 7 & AS, AA & 13 & 9 \\
\hline Patient 8 & MI, TI & 56 & 36 \\
\hline Patient 9 & MI, TI & 19 & 1 \\
\hline Patient 10 & MI & 27 & 4 \\
\hline
\end{tabular}

$M I$, Mitral insufficiency; $T I$, tricuspid insufficiency; $C H D$, coronary heart disease; $A S$, aortic stenosis; $A A$, ascending aneurysm. 


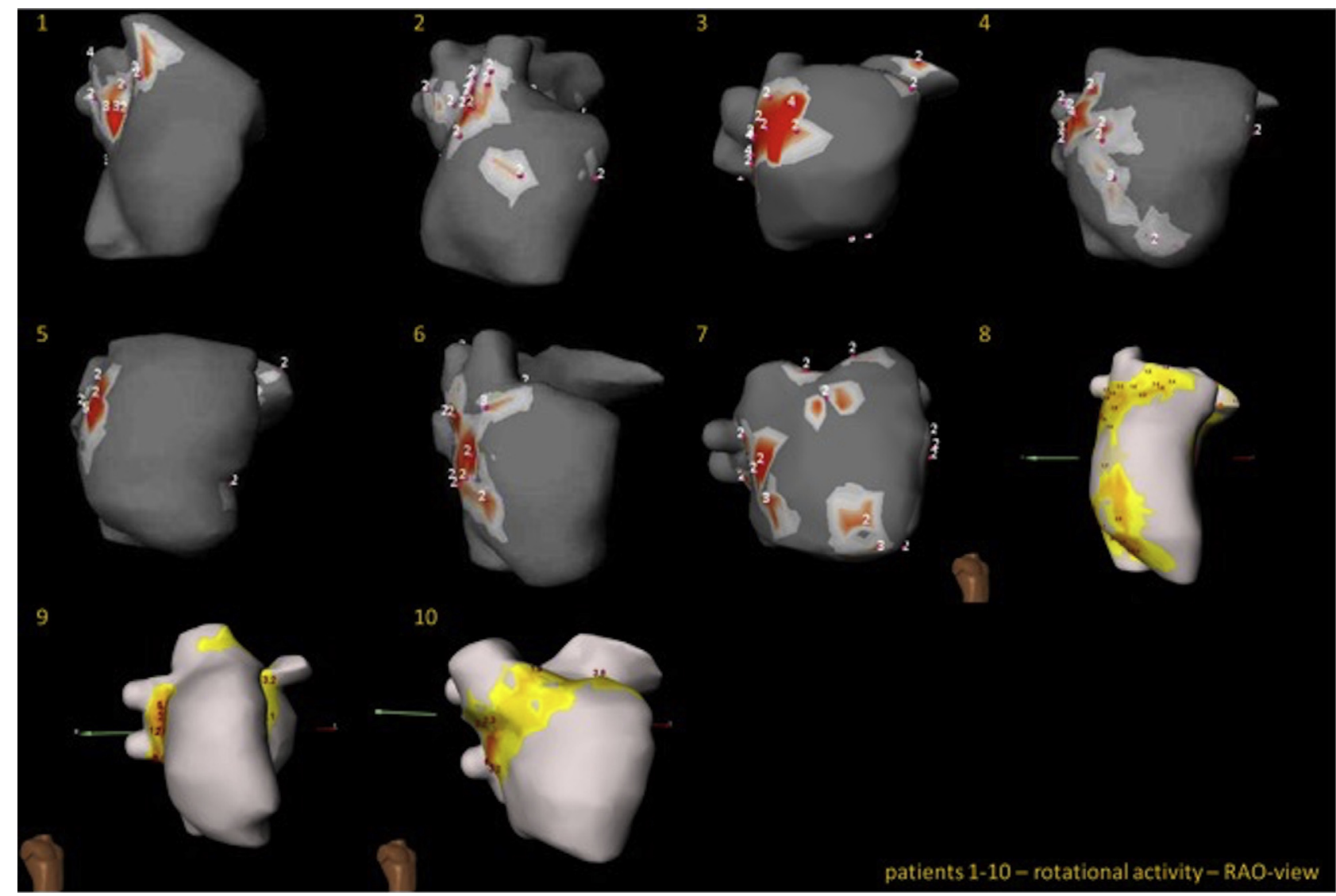

FIGURE 4. Rotor activity of all 10 patients. The first 7 patients were mapped with the first released version of the software, and the last 3 patients were already mapped with the upgraded version of the software: right anterior oblique view.

because we just have completed the 3-month follow-up. Nevertheless, 6 of 8 patients were in sinus rhythm at the 3 -month follow-up. However, this promising result needs to be confirmed at 6 and 12 months.

Second, all mapped focal and re-entrant activities in this study are located in atrial regions that are addressed with the Cox-Maze lesion set as described by $\operatorname{Dr}^{-C_{0}{ }^{13,14}}$ and are known to effectively treat the underlying fibrillation. The concept of the anatomic approach of the Cox-Maze procedure was based on experimental findings using a variety of canine models that were developed in the laboratory. They all had in common a series of atrial surgical incisions that were placed on the atria in an effort to prevent fibrillation. ${ }^{18}$ Regardless if one performs the original cutand-sew Maze procedure or uses an energy source such as bipolar radiofrequency or cryothermia, it is probably of paramount importance to create all lesion sets in an effort to eliminate persistent or long-standing persistent AF. Of note and in contrast to that observed by Haissaguerre and colleagues, ${ }^{12}$ we did not find that the amount of driver regions increased with the duration of continuous AF; however, our study is limited in size. We can also speculate that there might be some differences in the pathomechanism in concomitant AF compared with stand-alone AF.
Despite the remarkable success of the Cox-Maze procedure and the recent guidelines specifically demonstrating the outcome advantage associated with it, many surgeons and cardiologists are still reluctant to recommend and perform it. This is partly due to the wrong perception of risk and complexity associated with the procedure. Recent studies have shown that the Cox-Maze procedure does not have any additional surgical risk. ${ }^{19,20}$ Moreover, the procedure can decrease morbidity and mortality in concomitant surgical procedures and in high-risk patients with low ejection fractions. ${ }^{21}$

\section{Study Limitations}

This is a fairly small study in which a new commercial device was used. Therefore, longer-term follow-up and a larger subset of study patients are required before any clinical modifications can be recommended. Regardless, mapping was performed in all patients with excellent images and no technical difficulties.

\section{CONCLUSIONS}

This is the first report of the use of a noninvasive electrocardiomapping system in patients with cardiac disease undergoing a concomitant Cox-Maze procedure 
for persistent $\mathrm{AF}$. The results demonstrated re-entrant activity in both atria. The fact that a biatrial mechanism was detected in all patients suggests that a biatrial Cox-Maze III/IV procedure might be a reliable approach to treat patients with valvular heart disease and nonparoxysmal AF. Preoperative mapping has the potential to better guide the surgical ablation procedure of choice in a single patient. Further multicenter trials are needed to improve our understanding in the pathophysiology of AF.

\section{Conflict of Interest Statement}

M.P.E. reports speakers honoraria from Medtronic Inc; G.L. reports consulting fees from Edwards Lifesciences; M.P. is an engineer for Medtronic GmbH Meerbusch; M.A. reports a research grant from Edwards Lifesciences; N.A. reports speakers honoraria from Medtronic Inc. All other authors have nothing to disclose with regard to commercial support.

\section{References}

1. Kannel WB, Wolf PA, Benjamin EJ, Levy D. Prevalence, incidence, prognosis, and predisposing conditions for atrial fibrillation: population-based estimates. Am J Cardiol. 1998;82:2N-9N.

2. Stewart S, Hart CL, Hole DJ, McMurray JJ. A population-based study of the long-term risks associated with atrial fibrillation: 20-year follow-up of the Renfrew/Paisley study. Am J Med. 2002;113:359-64.

3. Jalife J. Rotors and spiral waves in atrial fibrillation. J Cardiovasc Electrophysiol. 2003;14:1665-80.

4. Narayan SM, Krummen DE, Shivkumar K, Clopton P, Rappel WJ, Miller JM. Treatment of atrial fibrillation by the ablation of localized sources: CONFIRM (conventional ablation for atrial fibrillation with or without focal impulse and rotor modulation) trial. J Am Coll Cardiol. 2012;60:628-36.

5. Lim HS, Hocini M, Dubois R, Denis A, Derval N, Zellerhoff S, et al. Complexity and distribution of drivers in relation to duration of persistent atrial fibrillation. J Am Coll Cardiol. 2017;69:1257-69.

6. Shah AJ, Hocini M, Pascale P, Roten L, Komatsu Y, Daly M, et al. Body surface electrocardiographic mapping for non-invasive identification of arrhythmic sources. Arrhythm Electrophysiol Rev. 2013;2:16-22.

7. Konrad T, Theis C, Mollnau H, Sonnenschein S, Rostock T. Body surface potential mapping for mapping and treatment of persistent atrial fibrillation. Herzschrittmacherther Elektrophysiol. 2014;25:226-9.
8. Ammar-Busch S, Reents T, Knecht S, Rostock T, Arentz T, Duytschaever M, et al. Correlation between atrial fibrillation driver locations and complex fractionated atrial electrograms in patients with persistent atrial fibrillation. Pacing Clin Electrophysiol. 2018;41:1279-85.

9. Oster HS, Taccardi B, Lux RL, Ershler PR, Rudy Y. Noninvasive electrocardiographic imaging: reconstruction of epicardial potentials, electrograms, and isochrones and localization of single and multiple electrocardiac events. Circulation. 1997;96:1012-24.

10. Rudy Y, Burnes JE. Noninvasive electrocardiographic imaging. Ann Noninvasive Electrocardiol. 1999;4:340-59.

11. Molteni M, Polo Friz H, Primitz L, Marano G, Boracchi P, Cimminiello C. The definition of valvular and non-valvular atrial fibrillation: results of a physicians' survey. Europace. 2014;16:1720-5.

12. Haissaguerre M, Jais P, Shah DC, Takahashi A, Hocini M, Quiniou G, et al. Spontaneous initiation of atrial fibrillation by ectopic beats originating in the pulmonary veins. N Engl J Med. 1998;339:659-66.

13. Cox JL. The surgical treatment of atrial fibrillation. IV. Surgical technique. J Thorac Cardiovasc Surg. 1991;101:584-92.

14. Cox JL, Schuessler RB, D’Agostino HJ, Stone CM, Chang BC, Cain ME, et al. The surgical treatment of atrial fibrillation. III. Development of a definitive surgical procedure. J Thorac Cardiovasc Surg. 1991;101:569-83.

15. Gillinov AM, Gelijns AC, Parides MK, DeRose JJ Jr, Moskowitz AJ, Voisine P, et al; CTSN Investigators. Surgical ablation of atrial fibrillation during mitral-valve surgery. N Engl J Med. 2015;372:1399-409.

16. Phan K, Xie A, Tsai Y-C, Kumar N, La Meir M, Yan TD. Biatrial ablation vs. left atrial concomitant surgical ablation for treatment of atrial fibrillation: a meta-analysis. Europace. 2015;17:38-47.

17. Knecht S, Sohal M, Deisenhofer I, Albenque JP, Arentz T, Neumann T, et al. Multicentre evaluation of non-invasive biatrial mapping for persistent atrial fibrillation ablation: the AFACART study. Europace. 2017; 19:1302-9.

18. Boineau JP, Schuessler RB, Mooney C, et al. Natural and evoked atrial flutter due to circus movement in dogs. Am J Cardiol. 1980;45:1167-81.

19. Rankin JS, Grau-Sepulveda MV, Ad N, Damiano RJ Jr, Gillinov AM, Brennan JM, et al. Associations between surgical ablation and operative mortality following mitral valve procedures. Ann Thorac Surg. 2018;105: 1790-6.

20. Ad N, Holmes SD, Pritchard G, Shuman DJ. Association of operative risk with the outcome of concomitant Cox Maze procedure: a comparison of results across risk groups. J Thorac Cardiovasc Surg. 2014;148:3027-33.

21. Ad N, Henry LL, Holmes SD, Hunt SL. The impact of surgical ablation for atrial fibrillation in high-risk patients. Ann Thorac Surg. 2012;93: 1897-904.

Key Words: atrial fibrillation, noninvasive mapping, CardioInsight 